This item was submitted to Loughborough's Research Repository by the author.

Items in Figshare are protected by copyright, with all rights reserved, unless otherwise indicated.

\title{
The Mathematics Learning Support Centre at Loughborough University: staff and student perceptions of mathematical difficulties
}

\section{PLEASE CITE THE PUBLISHED VERSION}

http://www.engsc.ac.uk/journal/index.php/ee/article/view/57/88

\section{PUBLISHER}

(C) HEA Engineering Subject Centre Loughborough University

VERSION

VoR (Version of Record)

\section{LICENCE}

CC BY-NC-ND 4.0

\section{REPOSITORY RECORD}

Perkin, Glynis, Godfrey Pell, and Tony Croft. 2019. "The Mathematics Learning Support Centre at Loughborough University: Staff and Student Perceptions of Mathematical Difficulties”. figshare. https://hdl.handle.net/2134/9461. 
This item was submitted to Loughborough's Institutional Repository (https://dspace.lboro.ac.uk/) by the author and is made available under the following Creative Commons Licence conditions.

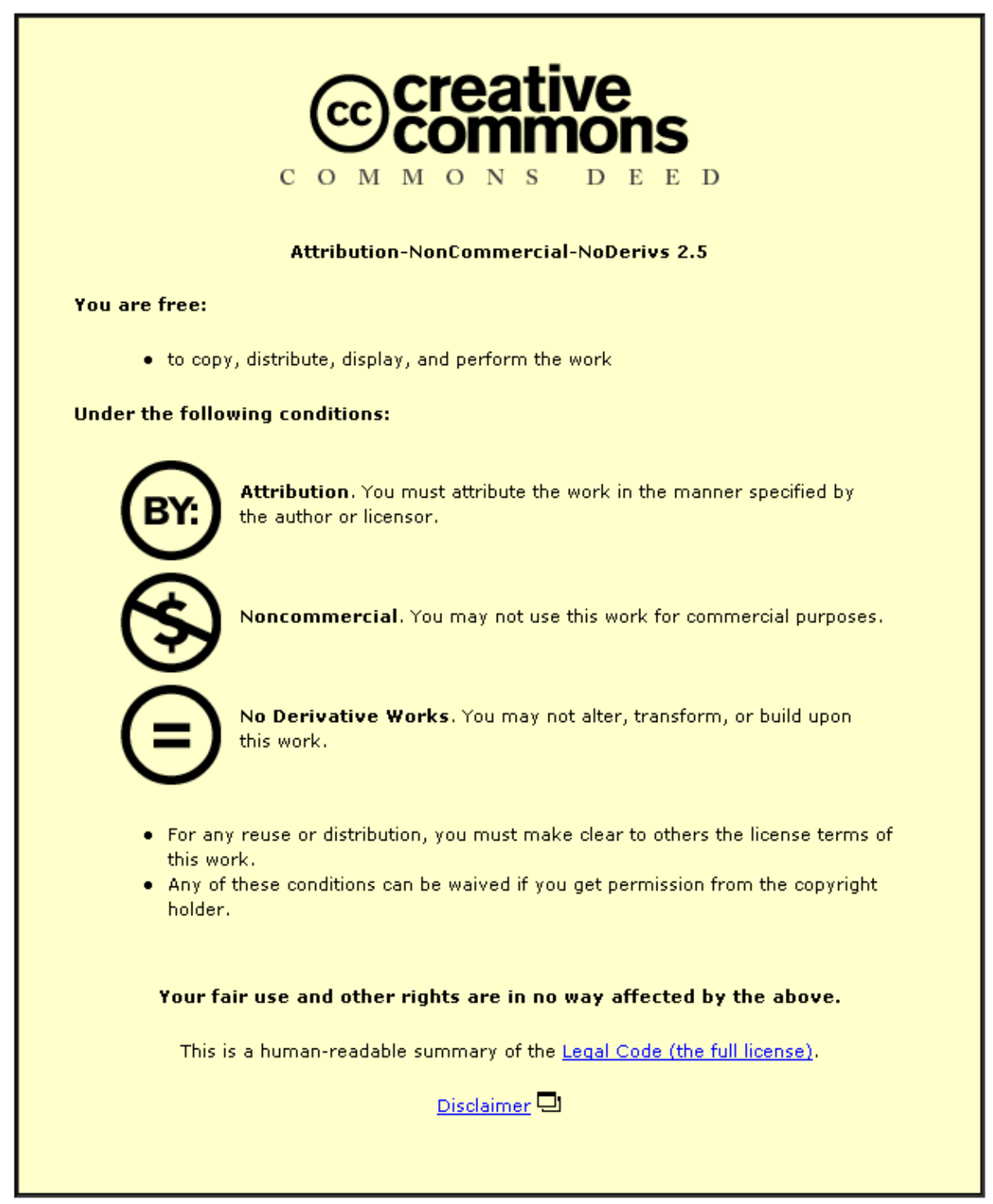

For the full text of this licence, please go to: http://creativecommons.org/licenses/by-nc-nd/2.5/ 


\title{
The Mathematics Learning Support Centre at Loughborough University: staff and student perceptions of mathematical difficulties
}

\author{
Glynis Perkin, Godfrey Pell and Tony Croft
}

\begin{abstract}
From a census of academic and academicrelated staff in the School of Mathematics at Loughborough University, most of whom work in the Mathematics Learning Support Centre, and a survey of the students who frequently use this facility we investigate the difficulties that are encountered with mathematics and the growing need for support with this subject. This paper reports the raw data results obtained from a selection of the questions that were posed. Responses were obtained from 29 mathematics staff and $\mathbf{3 7}$ students from mathematics, engineering and physics departments. We detail findings from the questions pertaining to perceptions of pre-knowledge, areas of difficulty and reasons for using the Centre. The results show that in some cases the opinions and perceptions of staff and students are almost diametrically opposite and in some cases students are unaware that the difficulties they are experiencing stem from a lack of fluency in areas of basic mathematics. What is also shown is that staff need to be aware of the mathematical content contained in the wide range of qualifications that students may enter university with. These findings have important consequences for those involved with mathematics education in the Higher Education sector and will also prove informative for universities who provide similar support.
\end{abstract}

\section{Introduction}

This paper presents some of the findings from an investigation undertaken at Loughborough University into student and staff perceptions of mathematical difficulties and mathematics support. With the increasing number of students visiting the Mathematics Learning Support Centre (MLSC) at Loughborough University, it was considered important to determine if the Centre was meeting the requirements of the students who use it and why they consider such support is necessary. The results of this study will be of benefit to those involved with teaching and learning in Higher Education (HE) and will also prove useful for those who provide mathematical support. At Loughborough University we have a model MLSC located within the Mathematics Education Centre, which has recently achieved Centre for Excellence in Teaching \& Learning status from the Higher Education Funding Council for England (HEFCE).

Since the arrival, at university, of the first candidates who had taken the GCSE examinations, there have been numerous journal articles and inquiries concerning the mathematical accomplishment of these students. In 1995 the report 'Tackling the Mathematics Problem' investigated concerns amongst mathematicians, scientists and engineers in $\mathrm{HE}$ about the mathematical preparedness of new undergraduates (LMS et al., 1995). Also in 1995 the Engineering Council commissioned a report to investigate speculation and anecdotal evidence concerning the changing mathematical background of undergraduate engineers. The findings showed, that amongst this body of students, mathematical knowledge was weaker than it had been 10 years previously (Sutherland \& Pozzi, 1995). On a wider scale, the Gatsby Charitable Foundation sponsored a seminar to investigate the same issue - in Departments of Mathematics, Physics and Engineering. Again, the findings showed strong evidence of a steady decline in basic mathematical skills and increasing variance in mathematical attainment and knowledge (Hawkes et al., 2000). The role of A Level mathematics has changed to that of an accessible part of general education and is 'no longer being designed as a tool for serving the needs of university mathematics' (Hoyles et al., 2001). There has, subsequently, been a number 
of government-funded inquiries, for example 'Inquiry Into A Level Standards' (Tomlinson, 2002), SET for success (Roberts, 2002) and Making Mathematics Count (Smith, 2004), investigating the suitability and standards of pre-19 qualifications; these all give credibility to the reality of the difficulties that are being experienced by both staff and students in numerate disciplines.

The HE sector has responded to these changes in several ways; many universities now use diagnostic testing to identify those students who are likely to experience difficulties with the mathematical elements of their courses. Those students identified as being at risk of failing are then often given follow-up support. Other routes that have been taken by university departments to cope with the teaching of mathematics to first year undergraduates include the redesigning of first year courses in mathematics, the provision of remedial assistance, drop-in support and computer based mathematics learning centres (Hawkes et al., 2000:3; LTSN MathsTEAM, 2002).

A study, funded by the Learning and Teaching Support Network (LTSN), was conducted in 2001 to determine the extent to which universities and Further Education (FE) institutions in the UK were providing mathematics support and to disseminate the findings. This study (Lawson et al., 2001 and 2002) established that 46 out of 95 (48\%) responding institutions did provide support for mathematics, over and above that given by tutorials. A later investigation into the provision of mathematics learning support in UK universities was undertaken by Perkin and Croft (2004) to determine whether there had been a rise or decline in the number of universities offering support, and the type of support available. This research was conducted solely in the HE setting in the UK, and 106 institutions, of which 101 (95\%) responded, were identified for the study. Of the responding universities, 66 (65\%) were found to offer some form of learning support for mathematics, which is additional to that provided by tutorials, personal tutor groups and problem classes.

\section{The study}

The staff census forms and student questionnaires for the MLSC investigation contained open and closed questions and were designed to serve several purposes, namely to:
- obtain staff perceptions of the mathematical ability of students they meet in tutorial groups and in the MLSC

- obtain student perceptions of the staff who work in the MLSC and the support that is available

- investigate particular areas of mathematical difficulty

- investigate awareness amongst staff and students of the services provided by the MLSC

- generate staff and student suggestions and requirements for an additional Centre.

There was a large overlap of questions in the staff and student forms to enable comparison of responses. For the questions reported in this paper we give the preliminary findings from our research. Of the staff and student responses, to be detailed later, some show close agreement whereas others show diametrically opposite points of view. Inevitably the numbers are statistically small; nevertheless, conclusions can be drawn from the raw data. These have implications for the professional development of the staff concerned and will inform future policy.

The study was conducted during the academic year 2004/2005 with the census forms being personally delivered to the 33 academic and academic related staff in the School of Mathematics, most of whom work or have worked in the MLSC. The census forms, consisting of 16 pages, split into six sections containing 63 questions, were distributed during December 2004. The six sections were:

Section 1: Personal Details

Section 2: General Questions

Section 3: Reasons for Having a MLSC

Section 4: Future Expansion and Development of the MLSC

Section 5: Suggestions

Section 6: Support in the MLSC.

Section six of the census form was to be completed only by those staff who had worked in the MLSC on a regular timetabled basis. The response rate obtained was close to $90 \%$. The 29 completed forms contained a large number of detailed comments and descriptive ideas. Of these responses, 23 members of staff had worked in the MLSC on a regular timetabled basis and six had not.

During the second semester of the same academic year a questionnaire was made available to students using the MLSC. This 
consisted of 14 pages, split into six sections containing 54 questions under the same headings as those included in the staff census forms. There were some identical questions, some additional questions and many questions asked from the opposite perspective. Personnel in the MLSC asked the students whom they recognised as frequent attendees to complete a questionnaire. Students who were new users of the Centre were not asked to participate as they would have insufficient knowledge of the Centre to answer many of the questions.

There were 37 completed questionnaires containing, in the main, a large amount of descriptive detail, additional information and suggestions. Of the student responses, 18 were registered in the School of Mathematics, 15 in Engineering Departments and four in Physics. Seven of the participating students did not have a GCE A Level in Mathematics.

To put the number of student responses in perspective, an attempt has been made to estimate the response rate. The statistics are, however, complicated by the fact that some students recognised as frequent attendees were in their second or later years of study and only attended the MLSC infrequently during the year of this study. To determine the response rate, it has, therefore, been decided to exclude six students who were in their second or later years of study who attended fewer than two times during the academic year 2004/2005. The foundation, first, second and higher year students who are included all attended seven or more times. During the second semester of the academic year 2004/2005 there were 2346 individual visits, 328 of which were made by students who completed the questionnaire. The total number of students who attended the MLSC on seven or more occasions during the second semester was 84 . Taking the 31 students who responded to the request to complete a questionnaire and attended on seven or more occasions gives an estimated response rate of $40 \%$.

\section{Preliminary analysis}

The staff census forms had requested the participants to register their age in one of three categories: under 35, 35-45 and 46 years of age or older. The student questionnaires had requested the students to record the age at which they had commenced their undergraduate studies.
The responses were then scrutinised to determine if there were any questions where the age of the participants was instrumental in producing a differing response. Where this has been evident, the information is also depicted in the age categories that have been defined.

Of the participating staff, 25 were male and four were female. Of the participating students, 26 were male and 11 were female. None of the questions reported herein produced a gender dependent answer.

\section{Analysis}

Both the staff census forms and the student questionnaires contained questions that were required to be answered in three different ways. One was the selection of a particular answer from a number of given options. However, there were many forms received, from both staff and students, where more than one option had been selected and additional comments appended. The second was the selection of all applicable answers from a number of given options; again additional comments were frequently appended. The third asked for suggestions to be given for improvement to the MLSC working environment.

The questions that were posed, to both staff and students, were designed to provide opportunity for analysis of a wide range of topics. As almost all members of staff (MLSC and non-MLSC) are responsible for personal tutee groups, some questions asked for staff opinions about these students; additionally staff who worked in the MLSC were also asked for their opinions about the students whom they encountered in the MLSC. This distinction was introduced to enable an additional comparison to be made. There were some questions where one or two members of staff did not provide an answer. This was due to their not having worked in the Centre for long enough to express an opinion or not being responsible for a tutorial group.

\section{Questions selected}

A total of six questions, which were posed to both staff and students, taken from sections 2 , 3 and 6 of the forms, are reported in this paper. The questions selected relate to perceived pre-knowledge, areas of difficulty and reasons for using the Centre. A bar chart representation shows the results of those questions where it was requested that all applicable options 
be selected and also those questions where respondents had selected more than one option. These bar charts show the number of times an option was selected, represented as the percentage of each population choosing that particular option. For questions where only one option has been selected the information is presented in a table, showing the number and percentage of non-MLSC staff, MLSC staff or students selecting it. Due to rounding, the response percentages do not always total $100 \%$.

\section{Results}

\section{(i) General questions} (taken from section 2 of the survey)

Q1. For what proportion of the students whom you encounter do you consider that their undergraduate course started at a higher level than their mathematical background had prepared them for? (Staff)

Did your university course start at a higher level than your mathematical background had prepared you for? (Students)

The staff and student responses are shown in Table 1.

Of the members of staff working in the MLSC, 12 out of 21 believed that for half or more of the students they encountered in the MLSC, their undergraduate course had started at a higher level than the students were prepared for. However, only 13 out of 37 of the students using the Centre believed this to be the case. For the students encountered in tutorial groups only 11 out of 28 of the MLSC and non-MLSC staff believed that for half or more of these students their undergraduate courses has started at a higher level that they were prepared for. These results indicate staff perception that many students face a daunting experience with university level mathematics and there is a need for the MLSC.

The majority of the students did not believe that their course had started at a higher level than their mathematical background had prepared them for; nevertheless, they frequently attended the MLSC. What is not clear is whether these students were purely conscientious or encountered difficulty due to the faster pace of learning at university. Yet when the staff responses are considered along with the 13 students who believed their mathematical background was inadequate, the indication is that many students face a daunting experience with university level mathematics.

The answers that were given by the students to this question were dependent upon their age at the commencement of their course and are shown in Table 2.

One student, in the 18 years of age category, who had stated that the undergraduate course had not started at a higher level than her

Table 1. Staff and student responses to question 1

\begin{tabular}{|c|c|c|c|c|c|}
\hline & \multicolumn{5}{|c|}{ Question 1} \\
\hline & \multicolumn{3}{|c|}{ Staff } & \multicolumn{2}{|c|}{ Students } \\
\hline & $\begin{array}{c}\text { Non-MLSC } \\
\text { Staff in } \\
\text { tutorial } \\
\text { groups (\%) }\end{array}$ & $\begin{array}{l}\text { MLSC Staff } \\
\text { in tutorial } \\
\text { groups (\%) }\end{array}$ & $\begin{array}{l}\text { MLSC Staff in } \\
\text { the MLSC (\%) }\end{array}$ & Options & (\%) \\
\hline & $n=6$ & $\mathrm{n}=\mathbf{2 2}$ & $n=21$ & \multicolumn{2}{|c|}{$n=37$} \\
\hline For all & 0 & 0 & 0 & Yes & $13(35.1)$ \\
\hline For almost all & $1(16.7)$ & $1(4.5)$ & $4(19.0)$ & No & $24(64.9)$ \\
\hline For more than half & $3(50.0)$ & $4(18.2)$ & $6(28.6)$ & & \\
\hline For about half & $1(16.7)$ & $1(4.5)$ & $2(9.5)$ & & \\
\hline For less than half & $1(16.7)$ & $15(68.2)$ & $9(42.9)$ & & \\
\hline For almost none & $0(0.0)$ & $0(0.0)$ & $0(0.0)$ & & \\
\hline For none & $0(0.0)$ & $1(4.5)$ & $0(0.0)$ & & \\
\hline
\end{tabular}


Table 2. Students by age - responses to question 1

\begin{tabular}{|l|c|c|c|}
\hline \multirow{2}{*}{} & \multicolumn{3}{|c|}{ Question $\mathbf{1}$} \\
\cline { 2 - 4 } & \multicolumn{3}{|c|}{ Students by age at commencement of course } \\
\hline \multirow{2}{*}{ Options } & $\mathbf{1 8}$ years old (\%) & $\mathbf{1 9 - 2 1}$ years old (\%) & 22 years old and over (\%) \\
\cline { 2 - 4 } & $\mathbf{n = 2 3}$ & $\mathbf{n}=\mathbf{1 1}$ & $\mathbf{n}=\mathbf{3}$ \\
\hline Yes & $6(26.1)$ & $5(45.5)$ & $2(66.7)$ \\
\hline No & $17(73.9))$ & $6(54.5)$ & $1(33.3$ \\
\hline
\end{tabular}

background had prepared her for appended the comment:

This was due to my having undertaken further mathematics and many of the topics I had spent considerable time on in further mathematics were brushed over quickly, without having taking this examination I would have been struggling.

Q2. For the students whom you encounter, what are the main areas in which they have problems? (Staff)

What are the main areas in which you experience mathematical difficulties? (Students)

Staff and students were requested to tick all applicable options.
The options given were:

- Basic manipulation

- Linear algebra

- Calculus

- Statistics

- Other.

Staff and student responses are shown in Figure 1.

In the category of 'other' members of staff appended the following comments:

- Concepts of mathematical proof

- Ability to think

- Difficulties in specific courses related to preuniversity background

- Algebra (2 staff)

- Logic and understanding what is being asked
Figure 1. Staff and student responses to question 2

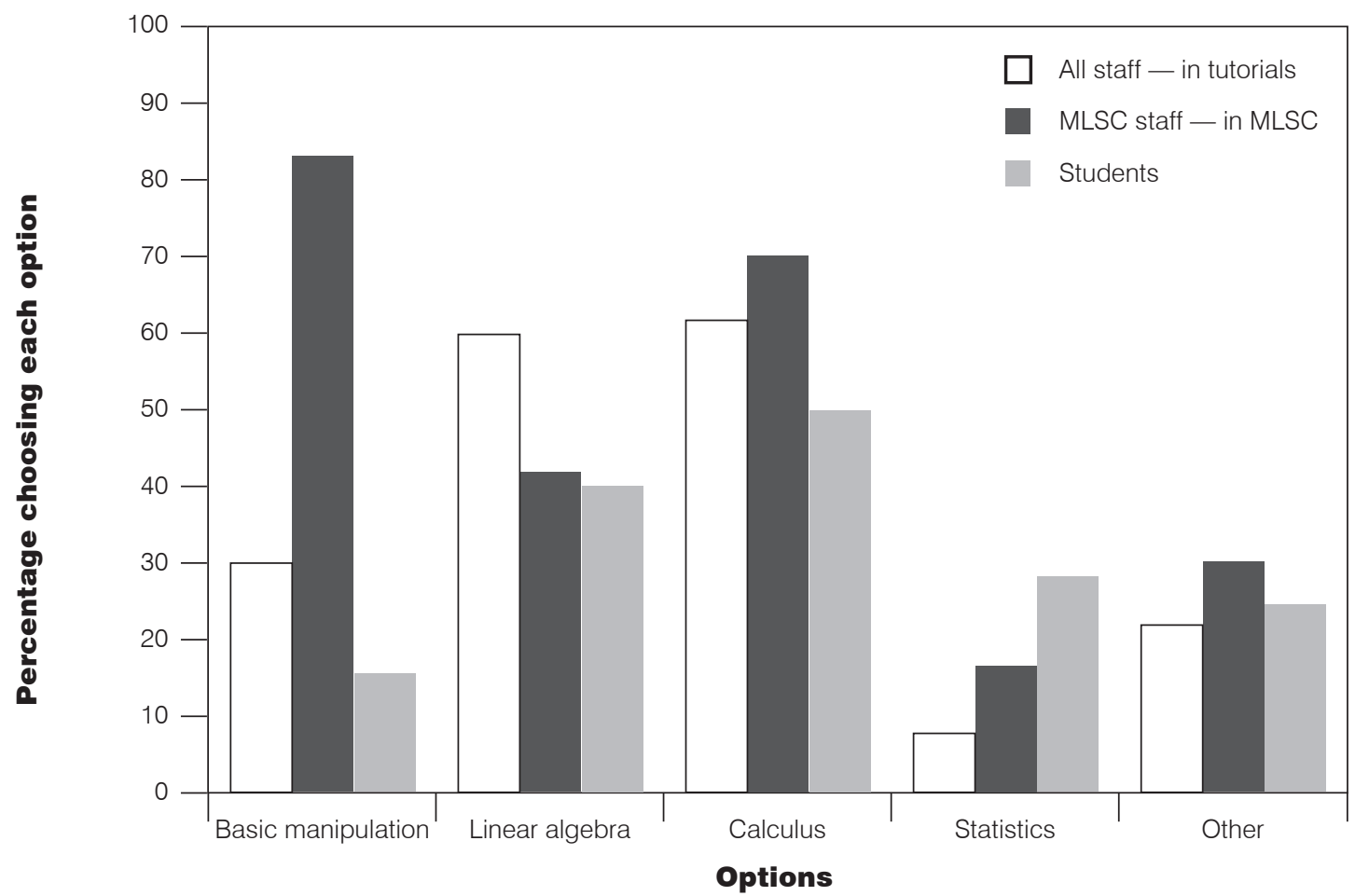


- Applied mathematical modelling and mechanics

- Engineering applications of mathematics

- Understanding the requirements of the question

- The formulation of the problem into a mathematical one

- Lack of practice in computer algebra packages such as Maple.

The eight comments that were recorded by the students were:

- Geometry

- Vectors

- Deeper use of topics, i.e., calculus in Fourier Series

- All pure mathematics

- Matrices (dyslexic student)

- My general mathematical ability

- Sequences and series

- Real analysis.

The responses to this question show a huge disparity between staff and student perceptions regarding the area of basic manipulation. This specific area of difficulty was most frequently chosen by MLSC staff and least frequently chosen by the students. This is a deep-rooted and recurring problem in HE. Students do not believe that they have a problem with this and hence do not address the issue. The responses also show staff and student perceptions to be at a different level; the staff comments were related to understanding whereas the student comments focused on specific topics.

\section{(ii) Reasons for having the Mathematics Learning Support Centre (taken from section 3 of the survey)}

Q3. Why are students seeking help with mathematics? (Staff and Students)

Staff and students were requested to tick all applicable options and their responses are shown in Figure 2.

The options given were:

- Increased academic level of courses

- Decrease in the knowledge of incoming students

- Increase in the number of dyslexic students

- Lowered academic recruitment level

- Students today demand/expect more support

- Other
None of the staff felt that students were seeking help due to increased academic level of courses yet over $50 \%$ of the students felt this was one of the reasons. Additionally, a high percentage of staff selected the option of lowered academic recruitment level, but only a low percentage of students attributed their reason for seeking help to this option. Again this highlights the difference between staff and student perceptions regarding the reason for mathematical support. It is reasonable to conjecture, however, that the majority of students are not in a position to view the given options objectively. The responses are in agreement with the findings of Tomlinson (2002), Roberts (2002) and Smith (2004) that there is, indeed, need for investigation into the content of GCE A Level mathematics and its suitability as a basis for HE courses with a high mathematical component. The authors are of the opinion that as $81 \%$ of the participating students had successfully completed mathematics GCE A Level, these students believed that their knowledge must be adequate. The reason, therefore, for mathematical support, must be that the university has increased the academic level of courses. Many of the problems being encountered, particularly amongst engineering students, may be attributed to the flexibility with module choice that is currently available in A Level mathematics. Mechanics modules provide a firm foundation for engineering, however, Lee et al., (2006), in a survey of approximately $20 \%$ of the schools in England, determined that over a quarter of these schools offer at most one mechanics module. Also, in an engineering context, they found that there appears to be disparity between incoming students' knowledge of mechanics and the prior knowledge that is expected by academics.

The answers that were given by the students to this question were dependent upon their age at the commencement of their course and are shown in Figure 3.

Of the students who commenced their studies at 18 years of age 15 out of 23 selected 'increased academic level of study', whilst none of the students who were 22 years of age or older at the commencement of their studies selected this option. This may be due to greater awareness amongst mature students of the changes that have taken place in A Level Mathematics syllabi. That these students have 
Figure 2. Staff and student responses to question 3

Figure 3. Students by age - responses to question 3
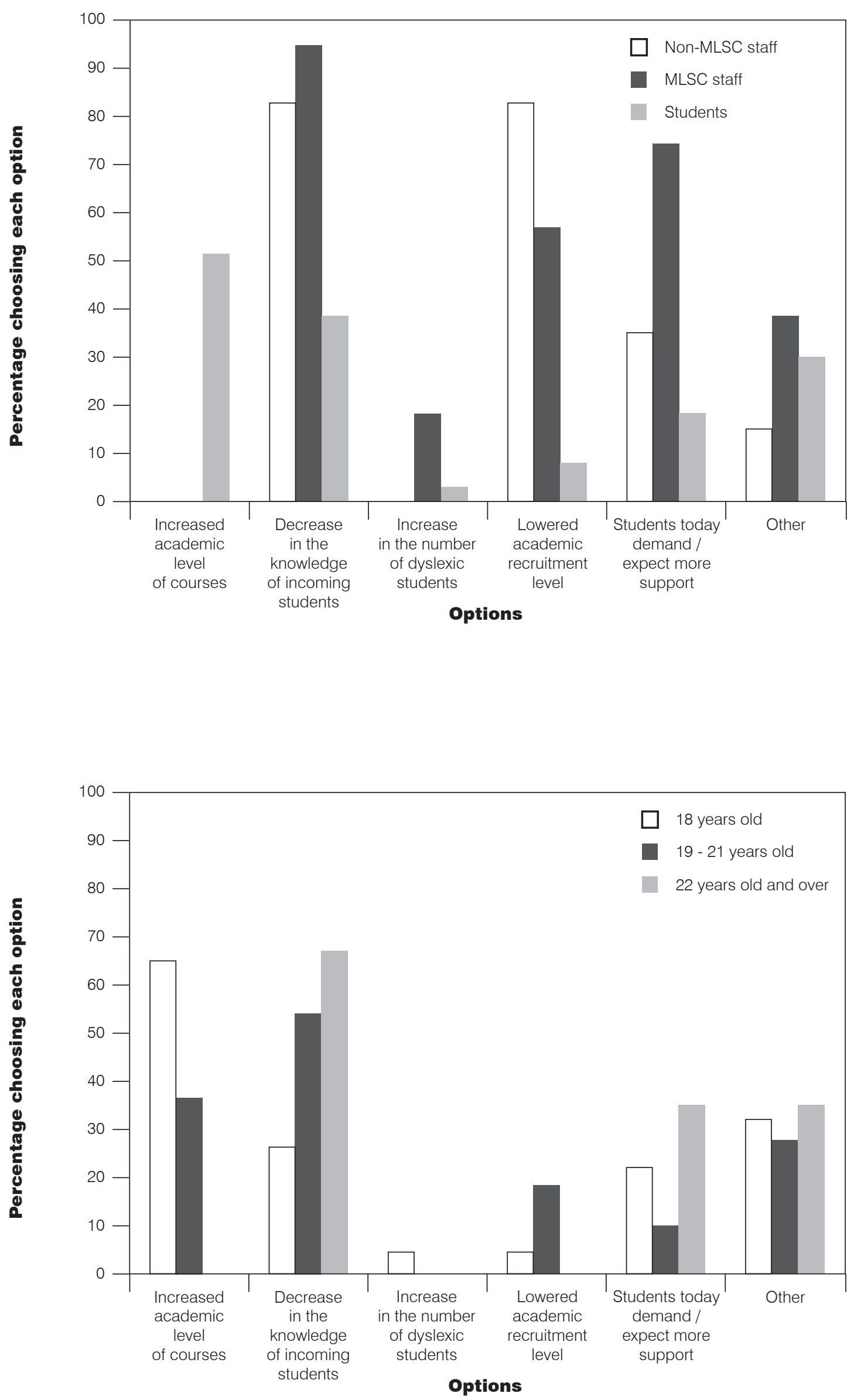
a different perception to many of the younger students is also shown by their selection of 'decrease in the knowledge of incoming students', and 'students today demand/ expect more support'.

The most frequent comments made by members of staff in the category 'other' were related to the availability of the facility, changes in the background of the students and the difficulty of mathematics. Examples of these comments are: 'Because it [the MLSC] is there and because it [mathematics] is hard'; 'Unrealistic expectations by some departments and staff'; and 'Inadequate knowledge by staff of the gap between demands of a course and the prerequisite knowledge and skills'.

The most frequent comments made by students in the category 'other' were related to the amount of new material that was encountered, the different method of delivery of material from that encountered at school, speed of delivery, lack of commitment before starting at university and laziness. Examples of these comments are: 'Different challenging aspects as mainly new material is being covered and often further clarification is required'; 'Students have been used to small classes with a good personal relationship with their tutors, university is a new method of teaching that many students are unfamiliar with'; 'Courses move quickly and lecturers expect students to instantly understand'; and 'Lack of commitment in mathematics before coming to university and too lazy to do selfstudy'.

\section{(iii) Support in the Mathematics Learning Support Centre (taken from section 6 of the survey)}

Q4. What do you consider is the most frequent reason for students using the MLSC? (Staff)

What is your most frequent reason for using the MLSC? (Students)

The options given were:

- Approaching examinations

- Coursework deadlines

- Other.

The staff and student responses are shown in Figure 4.

Although asked to tick the most frequent reason, some students and members of staff ticked more than one option. Only two members of staff selected the option 'other', with the comments that the Centre is used for problem sheets (weekly tutorial sheets that are handed out in lectures to provide practice on
Figure 4. Staff and student responses to question 4

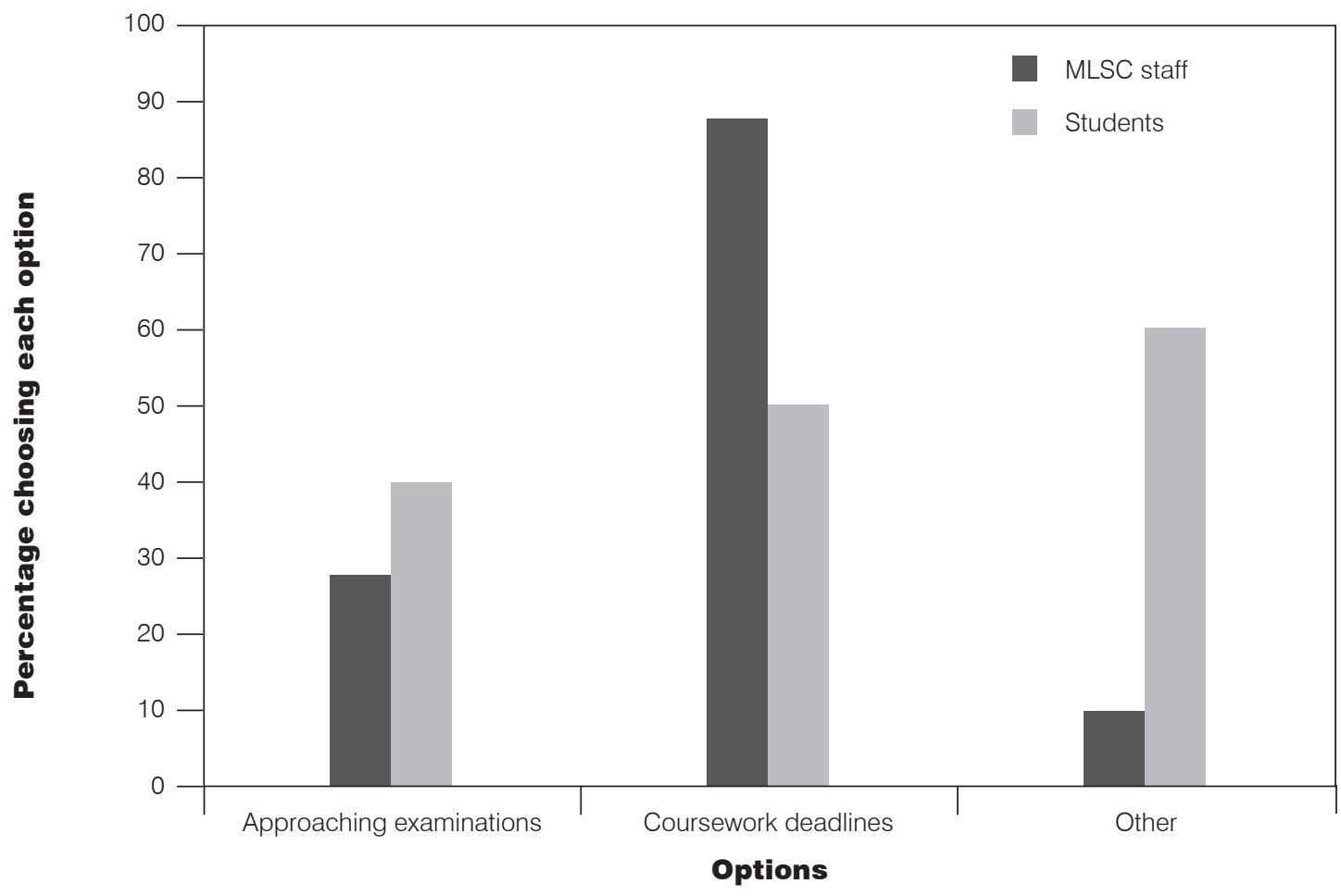


Figure 5. Students by age - responses to question 4

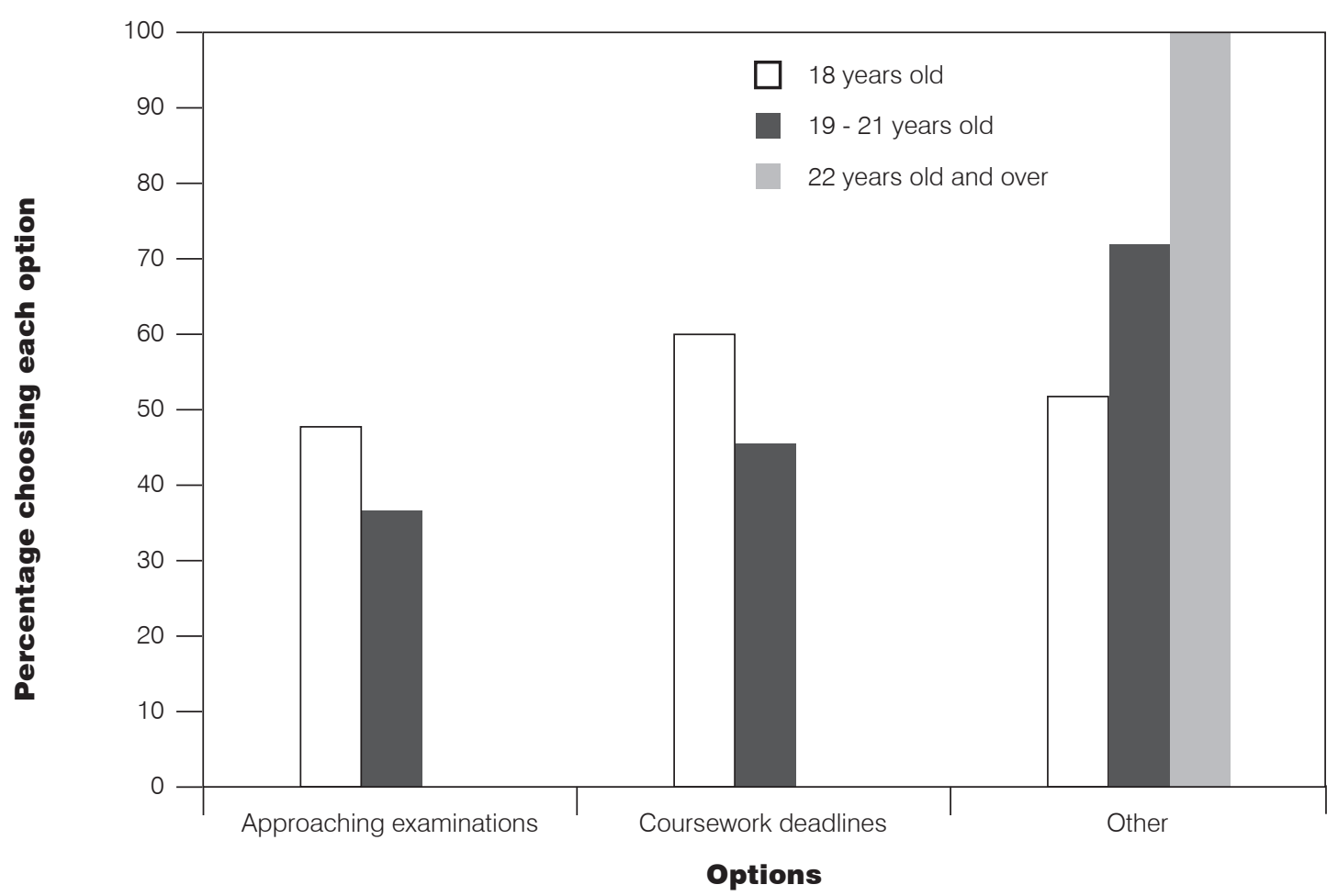

the topics that have been covered) and that students using the Centre want to learn, want to understand, want to do well and succeed. Of the students, 23 selected 'other', all mentioning that a reason for attending was to complete their weekly tutorial sheets.

The answers that were given by the students to this question were dependent upon their age at the commencement of their course and are shown in Figure 5.

None of the mature students selected approaching examinations or coursework

Table 3. Staff and student responses to question 5

\begin{tabular}{|c|c|c|}
\hline \multicolumn{3}{|c|}{ Question 5} \\
\hline \multirow{2}{*}{ Options } & MLSC Staff (\%) & Students (\%) \\
\hline & $n=23$ & $n=37$ \\
\hline All & $0(0.0)$ & $3(8.1)$ \\
\hline Almost all & $1(4.3)$ & $4(10.8)$ \\
\hline More than half & $15(65.2)$ & $7(18.9)$ \\
\hline About half & $6(26.1)$ & $12(32.4)$ \\
\hline Less than half & $1(4.3)$ & $7(18.9)$ \\
\hline Almost none & $0(0.0)$ & $4(10.8)$ \\
\hline None & $0(0.0)$ & $0(0.0)$ \\
\hline
\end{tabular}

deadlines as the most frequent reason for attending the Centre. Two of these students added that they had a genuine desire to understand all the lecture material.

Q5. What proportion of the time that students spend in the MLSC do you consider is due to approaching examinations or coursework deadlines? (Staff)

What proportion of your time spent in the MLSC is due to approaching examinations or coursework deadlines? (Students)

Staff and student responses are shown in Table 3.

More than half the staff believed that the students' most frequent reasons for using the MLSC were approaching coursework deadlines and examinations. The students' responses to this question produced a slight contradiction as 26 of them stated that they spent half or more of their time in the MLSC due to approaching examinations or coursework deadlines, yet more than half of them had cited the most frequent reason for using the MLSC was the completion of tutorial sheets (Q4).

Q6. For students who were unable to understand your initial explanation, for what proportion of them was this lack of understanding due to their mathematical 
Table 4. Staff and student responses to question 6

\begin{tabular}{|l|c|c|}
\hline \multicolumn{3}{|c|}{ Question 6 } \\
\hline \multirow{2}{*}{ Options } & MLSC Staff (\%) & Students (\%) \\
\cline { 2 - 3 } & $\mathbf{n}=\mathbf{2 1}$ & $\mathbf{n}=\mathbf{3 7}$ \\
\hline All & $0(0.0)$ & $3(8.1)$ \\
\hline Almost all & $5(23.8)$ & $7(18.9)$ \\
\hline More than half & $6(28.6)$ & $5(13.5)$ \\
\hline About half & $4(19.0)$ & $5(13.5)$ \\
\hline Less than half & $4(19.0)$ & $8(21.6)$ \\
\hline Almost none & $1(4.8)$ & $5(13.5)$ \\
\hline None & $1(4.8)$ & $4(10.8)$ \\
\hline
\end{tabular}

background being weaker than was immediately apparent? (Staff)

If there have been occasions when you were unable to understand the initial explanation given by a lecturer, how often was this due to the lecturer assuming that your underlying mathematical background is greater than it actually is? (students)

Staff and student responses are shown in Table 4.

It appears that more staff than students believe that it is a lack of understanding of topics underpinning the mathematics encountered in $\mathrm{HE}$ that is having a detrimental effect on comprehension. Nevertheless, the responses indicate that staff working in the MLSC are aware of the students' level of mathematical knowledge and understanding.

\section{Discussion and concluding remarks}

The study shows that some staff believe university courses start at a higher level than the students' background has prepared them for. A frequent reason for students not understanding an initial explanation is probably due to their mathematical background being weaker than was first believed. This is clearly an area that needs greater staff development. Provision needs to be made to ensure that staff are aware of current school mathematics syllabi, proposed changes to syllabi, differing entry qualifications and the pre-university depth at which mathematical topics are covered.
The greatest differences of opinion between staff and students occurred in:

- the areas where mathematical difficulties were being experienced

- why students are seeking help

- reasons for using the MLSC.

Whilst there was a huge disparity over whether basic manipulation was seen as an area of difficulty, it was also evident in the responses to Q2 that staff and students have a very different conceptualisation of 'areas of difficulty'. The comments made by staff referred mainly to lack of logic and understanding whereas students generally referred to specific mathematical topics. Regarding basic manipulation, there appears to be a huge chasm between staff and student perceptions. Staff perceive a fundamental weakness, whereas students see a problem with the question being posed, which again indicates that staff need a greater awareness of current school mathematics syllabi and the level at which topics are delivered. It is of concern that in their response to Q4 the majority of staff are of the opinion that students most frequently use the Centre to obtain help with coursework or for approaching examinations, whereas 23 of the students indicated that they were attending to complete their tutorial sheets with many of them adding that they wanted to understand and succeed.

It is evident that some staff need greater familiarity with the background of those students who are entering HE to read for a degree with a high level of mathematical content. Staff also need to be aware that whilst some students may be weak in what are considered to be fundamental skills, many of these students are concerned about their difficulties, attending the MLSC and attempting tutorial sheets in an endeavour to gain understanding. An interesting point to emerge is that students do not seem to appreciate that it is often lack of understanding of basic and fundamental mathematics that is at the root of their problems. This has implications for any attempts by staff to encourage students to undertake remedial work since students do not believe that they need to. This is an issue that presents universities with a major challenge.

That there is a necessity for mathematical support in HE is evident. The numerous changes to A Level mathematics syllabi have resulted in underlying weaknesses in many 
areas that were once considered strong and it is no longer possible to assume an in-depth understanding in these areas. Familiarity with basic manipulation and algebra are essential for progression on courses with a high mathematical content, and it is evident that additional support is required in these areas. Additionally, there are some courses where difficulty to recruit sufficient numbers has resulted in applicants being accepted with lower academic achievements than has previously been the case. At the present time it is not possible for admission tutors to ascertain whether a GCSE mathematics qualification has been obtained at the higher level or the intermediate level (which has minimal algebraic content).

It is also apparent that staff need to be aware not just of syllabi changes but also the many routes through which students are now entering
$\mathrm{HE}$ in addition to the traditional $\mathrm{A}$ Level, for example, Access and BTEC courses, and also to appreciate the differences between these modes of study.

Similar research to that discussed in this paper could be undertaken across a range of universities that offer mathematics learning support; this would determine if the findings at Loughborough University are typical within other institutions. Another question that arises is whether universities should be pro-active and introduce learning contracts for students, thus committing students to address their mathematical weaknesses. In this context, on-ground research into the amount of resources made available for the provision of mathematics support and the obligations of students entering HE needs to be undertaken.

\section{References}

Hawkes, T. \& Savage, S., eds. (2000) Measuring the Mathematics Problem. London: The Engineering Council.

Hoyles, C., Newman, K. \& Noss, R. (2001) Changing Patterns of transition from school to university mathematics. International Journal of Mathematical Education in Science. 32 (6) 829-845.

Lawson, D., Halpin, M. \& Croft, T. (2001) After the diagnostic test - what next? MSOR Connections, 1 (3) 19-23.

Lawson, D., Halpin, M. \& Croft, T. (2002) After the diagnostic test - what next? Part 2. MSOR Connections, 2 (1) 23-26.

Lee, S., Harrison, C. \& Robinson, C.L. (2006) Engineering students' knowledge of mechanics upon arrival: expectation and reality. Engineering Education Journal of the Higher Education Academy Engineering Subject Centre. 1 (1) 32-38.

LMS., IMA., RSS. (1995) Tackling the Mathematics Problem. London: London Mathematical Society.

LTSN MathsTEAM (2002) Maths support for students. LTSN MathsTEAM Project. Available from http://www.engsc.ac.uk/downloads/mathsteam/student_support.pdf [Accessed 14 March 2007].

Perkin, G. \& Croft, T. (2004) Mathematics Support Centres - the extent of current provision. MSOR Connections, 4 (2) 14-18.

Roberts, G. (2002) SET for success: the supply of people with science, technology, engineering and mathematics skills. London: HM Treasury.

Smith, A. (2004) Making Mathematics Count, the report of Professor Adrian Smith's Inquiry into Post-14 Mathematics Education 2/04 037764. London: The Stationery Office.

Sutherland, R. \& Pozzi, S. (1995) The Changing Mathematical Background of Undergraduate Engineers: a review of the issues. London: The Engineering Council.

Tomlinson, M. (2002) Inquiry into A Leve/ Standards. Available through Prolog. Telephone: 0845 6022 260, Fax: 08456033 260. Reference Code TMN2. 


\section{About the authors}

Glynis Perkin (Principal Author) MMath (Hons)

Progression Project Officer, Engineering Centre for Excellence in Teaching and Learning/ Mathematics Education Centre, Loughborough University, Leicestershire, LE11 3TU.

Email: G.Perkin@lboro.ac.uk

Godfrey Pell BEng, MSc, FRSS, CStat.

Visiting Fellow, Mathematics Education Centre, Loughborough University, Leicestershire, LE11 3TU.

Senior Statistician, School of Education, University of Leeds, Leeds, LS2 9JT.

Email: G.Pell@leeds.ac.uk

Tony Croft BSc (Hons), MPhil, PhD., CMath, FIMA, MILT

Director of the Mathematics Education Centre, Loughborough University, Leicestershire,

LE11 3TU.

Email: A.C.Croft@lboro.ac.uk 